\title{
THREE-DIMENSIONAL MARGINAL BONE LOSS AROUND IMPLANTS SUPPORTING FIXED METAL-CERAMIC PROSTHESIS AND IMPLANT OVERDENTURES USING CBCT IN PATIENTS WITH MANDIBULAR EDENTULOUS RIDGES. A 3-YEARS RANDOMIZED CLINICAL TRIAL
}

\author{
Ahmed Ibrahim Mahrous* and Hisham Mohamed Abba***
}

\begin{abstract}
Purpose: The aim of this randomized controlled study was to compare three-dimensional marginal bone loss around implants supporting fixed metal-ceramic prosthesis and implant overdentures in patients with mandibular edentulous ridges.

Materials and methods: Twelve completely edentulous patients were randomly assigned into two groups; 1) Group A (fixed prosthesis); patients received 6 implants (4 in the interforaminal area, and 2 posterior to the mental foramina) and fixed full arch screw-retained porcelain fused to metal restoration, 2) Group B (overdenture prosthesis); patients received four implants in the interforaminal area and the implants were connected to overdentures with locator attachments. For each participant, Three-Dimensional bone loss was measured at mesial, distal, buccal and lingual surface of each implants using cone beam computerized tomography (CBCT) which was made at time of prosthesis insertion, one year, and 3 years after insertion
\end{abstract}

Results: For all implant surfaces except lingual surface, the overdenture group showed significantly higher marginal bone loss than fixed prosthesis after one years and 3 years. For fixed prosthesis group, the highest bone resorption after one and 3 years was observed in the lingual site and the lowest marginal bone loss was observed at buccal site. For overdenture group, the highest bone loss observed at the buccal site, and the lowest one loss was observed at lingual site (after one year) and distal site (after 3 years). For both groups, bone loss after 3 years was significantly higher than after one year.

Conclusion: Within the limits of this randomized controlled study, fixed prosthesis was associated with reduced Three-Dimensional marginal bone loss compared to overdentures prosthesis after one and three years of prosthesis insertion.

* Associate Professor of Prosthodontics, Restorative Department, Vision Colleges, Jeddah. KSA

** Lecturer of Oral and Maxillofacial Radiology, Department of Oral and Maxillofacial Radiology, Faculty of Dentistry, Cairo University, Egypt 


\section{INTRODUCTION}

Fully edentulous is irreversible problem affecting quality of life. This condition is associated with impaired mastication, speech, aesthetics, and psychological problems ${ }^{1}$. The rehabilitation of edentulous mandibular ridge using dental implants can be performed using fixed or removable restorations ${ }^{2,3}$. If sufficient bone exists above mandibular canal, six two eight implants widely distributed along the entire arch is recommended to support fixed ceramometal restoration ${ }^{4}$. If the available bone only exists in the anterior segment of the mandible between the mental foramina (in case of ridge atrophy), several prosthetic options are available including; 1 ) the use of 4 or 5 implants in the interforaminal area to support fixed cantilevered prosthesis ${ }^{2}, 2$ ) the use of vertical and posterior inclined implants immediately loaded with fixed screw retained hybrid "All on 4 concept" ${ }^{5}, 3$ ) the use of overdentures supported by four interforaminal implants ${ }^{4,6}$.

The choice between fixed and removable restorations depends on several factors such as patients desire and expectations, cost of the prosthesis, oral hygiene and manual dexterity of the patient, the relation between maxillary and mandibular ridges, interforaminal space, and the anatomy of residual ridges ${ }^{7}$. The fixed full arch ceramometal restoration is indicated when there is minimum alveolar bone resorption, sufficient bone and sufficient restorative and interarch spaces exists ${ }^{8}$. On the other hand, implant overdentures are indicated when significant amount of bone loss occurred to restore facial support, avoid long crowns of fixed prosthesis, overcome occlusal problems resulted from classes II and III maxillomandibular ridge relationships ${ }^{9,10}$. In addition, the retrievability of overdentures by the patients can overcome hygienic, cleansing and bruxism problems that are usually associated with fixated restoration ${ }^{11}$. Generally, both hybrid fixed prosthesis (that replaces teeth and lost tissues with pink porcelain) and implant overdentures can be used to improve appearance when significant amount of hard and soft tissue loss exists ${ }^{12}$. There is no significant difference in the survival rate of implants supporting fixed and removable restorations used to rehabilitate the edentulous patient ${ }^{4}$.

The marginal bone loss around implants plays a crucial role in the overall success of any implant treatment and can significantly affect the clinical outcome $^{13,14}$. The amount of marginal bone loss that was assumed as normal in the literature is $1.0-1.5 \mathrm{~mm}$ during the first year and less than 0.2 $\mathrm{mm}$ per year annually ${ }^{13,14}$. If amount of marginal bone loss exceeds this limit, it may be an indication of increased risk of peri-implantitis which may affect the implant survival rate ${ }^{15}$. The marginal bone loss is a multifactorial phenomenon that is not fully understood. However, the main theories included infection/ surgical trauma and occlusal overload $^{15}$. From the prosthetic point of view, the pattern of force transmission to the procedures during mastication may differ in implant-supported fixed prosthesis form that in implant supported overdentures 16-18. Evaluation of peri-implant marginal bone resorption usually performed using standardized two-dimensional intraoral radiographs which can evaluate mesial and distal bone loss only. With the introduction of cone beam computerized tomography (CBCT), three-dimensional evaluation of marginal bone can be performed as buccal and lingual marginal bone loss can be assessed in the cross-sectional image of the CBCT ${ }^{19,20}$

Reviewing the literature, the evaluation of marginal bone resorption around implants supporting mandibular fixed ceramometal prosthesis and implant overdentures still scarce s1,22 $^{21}$ Moreover, these studies usually include overdentures supported with cantilevered bars and not include new attachments such as locator attachments which are simpler to use, have different retention values, have a low-profile, and can be used with angulated implants ${ }^{23-25}$. In addition, these studies neglected 
the evaluation of buccal and lingual marginal bone resorption around implants. The aim of this study was to compare three-dimensional marginal bone loss around implants supporting fixed metalceramic prosthesis and implant overdentures in patients with mandibular edentulous ridges. The null hypothesis was that no significant difference in marginal bone resorption will be obtained between fixed and removable restorations.

\section{MATERIALS AND METHODS}

\section{Participants}

A convenience sample of 12 edentulous patients ( 6 males and 6 females, mean age $=58.5$ years $)$ were selected for this randomized trial. The participants were completely edentulous and were dissatisfied with retention and stability of their mandibular dentures with obvious need of replacement of these by implant-supported prosthesis. Medical and dental history were obtained from all participants then clinical intraoral examination was performed. The eligibility criteria include: 1) patients having maxillary and mandibular complete dentures was adequate retention and stability of maxillary denture but the mandibular denture is lacking retention and stability, 2) good amount of bone quantity and quality anterior and posterior to the mental foramina to receive implants of at least $8 \mathrm{~mm}$ in length and $3.5 \mathrm{~mm}$ in width. This was assessed using cone beam computerized tomography (CBCT) performed before surgery. 2) sufficient restorative space (space between the mucosal and the occlusal plane of mandibular denture). Exclusion criteria included patients complained from local or general contraindication for implant placement such as bone metabolic disorders (Diabetes Mellitus, hyperparathyroidism), heart disease, liver disease and chemotherapy or radiation therapy to the head and neck region. All participants were informed about the study plan, then informed consents were obtained from all patients. The protocol of the study was approved by the local ethical committee of the faculty of dentistry.

In this parallel randomized controlled trial, the participants were randomly assigned into two groups of equal patient number; 1) Group A (fixed prosthesis, $n=6$ ); patients received 6 implants (4 in the interforaminal area, and one implant posterior to the mental foramen on both sides) and fixed full arch screw-retained porcelain fused to metal restoration, 1) Group B (overdenture prosthesis, $n=6$ ); patients received four implants in the interforaminal area and the implants were connected with overdentures with locator attachments. Randomization was performed by independent examiner using block randomization method and stratification of patient by gender to reduce the risk of bias and to achieve balancing between groups at baseline. Assignment of the patients to treatment groups was performed by a blind examiner. To avoid selection bias, each patient assignment group was labeled and concealed in sealed black envelopes, and the group identification was only revealed at the time of the implant surgery.

\section{Surgical and prosthetic interventions}

Existing maxillary dentures were examined for each participant. If the retention and stability aesthetics and occlusion of maxillary dentures are adequate, new mandibular conventional dentures were constructed. The maxillary dentures are in adequate, new maxillary and mandibular dentures were constructed. The occlusion was constructed using semi-anatomic acrylic resin teeth and the bilateral balanced occlusal concept. The participants were instructed to wear the new dentures for at least one month to enhance muscular adaptation. The new mandibular dentures were replicated to be used as a radiographic stent by attaching gutta perchae radiopaque markers at proposed implant sites. Subsequently, each participant underwent a cone beam computerized tomography (CBCT, i- CAT Vision, Hatfield, PA, USA) to evaluate bone quantity 
and quality at implant positions and to evaluate proximity to vital structures. The radiographic stent was then converted to surgical stent by attaching metal tubes parallel to each other's at proposed implant sites using a dental surveyor.

For fixed prosthesis group, a crestal incision and full-thickness mucoperiosteal flap was elevated from first molar area of one side to first molar area of the other side. Osseous bone recontouring was performed with sharp knife edge ridges if needed to provide at least $1 \mathrm{~mm}$ buccal and lingual to each implant to prevent future bone loss. Six implants (Dentium, South Korea) were installed (4 in the interforaminal area, and one implant posterior to the mental foramen on both sides) using conventional submerged (2-stage) surgical approach. At least $35 \mathrm{Ncm}$ torque was required at implant insertion to achieve primary implant stability. Cover screws were connected to the implants and the flap was closed using multiple interrupted sutures. The mandibular dentures were relined with tissue conditioner material (COE-Comfort, U.S.A) and occlusion was adjusted. Post-operative medications include analgesics (Ketolac ${ }^{\circledR} 10 \mathrm{mg}$ ), antibiotics (amoxicillin $625 \mathrm{mg}+$ clavulanic acid $125 \mathrm{mg}$, Augmentin $\AA 1 \mathrm{gm})$, mouth rinse for 2 weeks and anti-inflammatory medication (ibuprofen ${ }^{\circledR}$, $600 \mathrm{mg}$ ) for 7 days. Three months after surgery, healing abutments were connected. Two weeks later, Open tray impression procedure was started. Long impression posts were treated to the implant platform and splinted with Duralay resin (Reliance, USA) which is minimal shrinkage on setting to prevent movement of the impression posts during impression removal (fig1a). Light body rubber base impression material was injected around the impression posts and the overall impression was completed using putty material (Zhermack ${ }^{\circledR}$, Badia Polesine, Rovigo, Italy). Implant analogues were attached to the impression posts and the impression was poured using hard stone. Recorded bases were constructed record jaw relations and facial support. Ti-base abutments (Dentium, Korea) were threaded to the implant analogues and the mother was scanned using CAD/CAM device (Ceramill, Austria), then a fixed screw-retained hybrid prosthesis was designed with 12 teeth (from first molar on one side to first molar on the other side) then printed into castable resin and tried in patient mouth (fig $1 \mathrm{~b}$ ). The resin

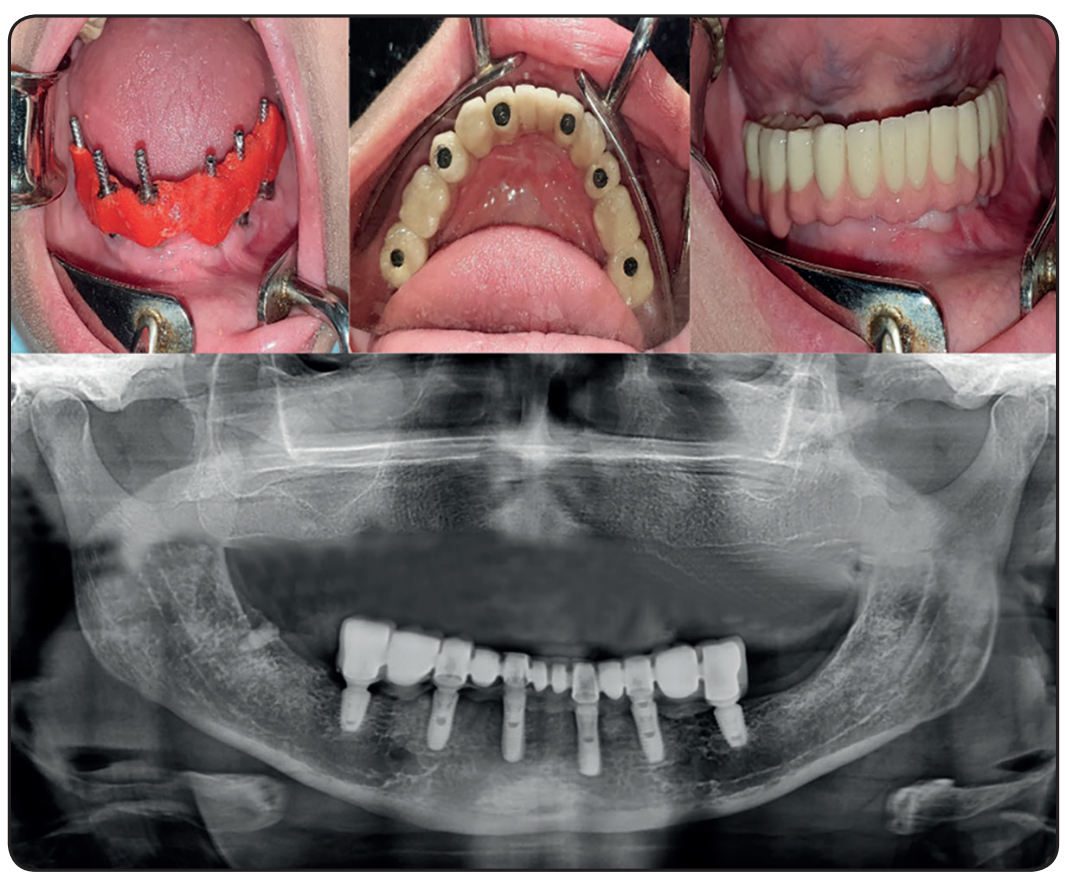

Fig. (1). The fixed prosthesis group; a) splinting of the impression post using Duralay resin, b) occlusal view of the prosthesis, c) the buccal review of the prosthesis, $d$ ) panoramic view of the prosthesis 
bridge was invested, cast with Cobalt chromium alloy, tried in for passive fit using single screw test. The porcelain powder (VITA, Germany) was mixed, applied onto the metal over the opaque layer, fired, finished and glazed. Pink porcelain was used to replace lost bone and gingival tissues when needed (fig 1c). Fixed prostheses were delivered to all patients and panoramic radiographs were made to ensure passive seating of the prosthesis (fig1d)

For overdenture prosthesis group, a crestal incision and full-thickness mucoperiosteal flap was elevated from premolar area of one side to premolar area of the other side. Osseous bone recontouring was performed if needed. Four implants (Dentium, South Korea) were installed in the interforaminal area using conventional submerged (2-stage) surgical approach. The flap was closed using multiple interrupted sutures. The mandibular dentures were relined with tissue conditioner material. After three months, the tissue conditioning material was replaced with hard acrylic resin relining. Locator abutments (Dentium, South Korea) were threaded to the implants at $20 \mathrm{Ncm}$ torque. Panoramic x-ray was performed to ensure complete seating of locator abutments (fig 2a). Rubber dam sheets were placed over the locator abutments to avoid contact of acrylic resin to the abutments and prevent excess resin to enter in peri-implant sulcus. Metal housing with processing inserts were snapped on the locator abutments (fig 2b). The mandibular dentures were relieved over the metal housings and lingual events were made and the lingual surface of the denture to allow escapement of excess acrylic resin during pick up procedure. The metal housings were picked to the tissue surface of the mandibular denture using autopolymerized acrylic resin while the participants close in centric relation (fig 2c). Excess acrylic resin was removed to avoid unnecessary loading of the implants and the denture was finished and polished. Processing inserts were replaced with nylon insert (medium retention) and dentures delivered to the participants. Participants were instructed for oral hygiene procedures and informed to attend regular follow-up visits.

\section{Measurement of Three-Dimensional bone loss} For each participant, Three-Dimensional bone loss was measured using cone beam computerized tomography (CBCT, i- CAT Vision, Hatfield, PA, USA) which was made at time of prosthesis

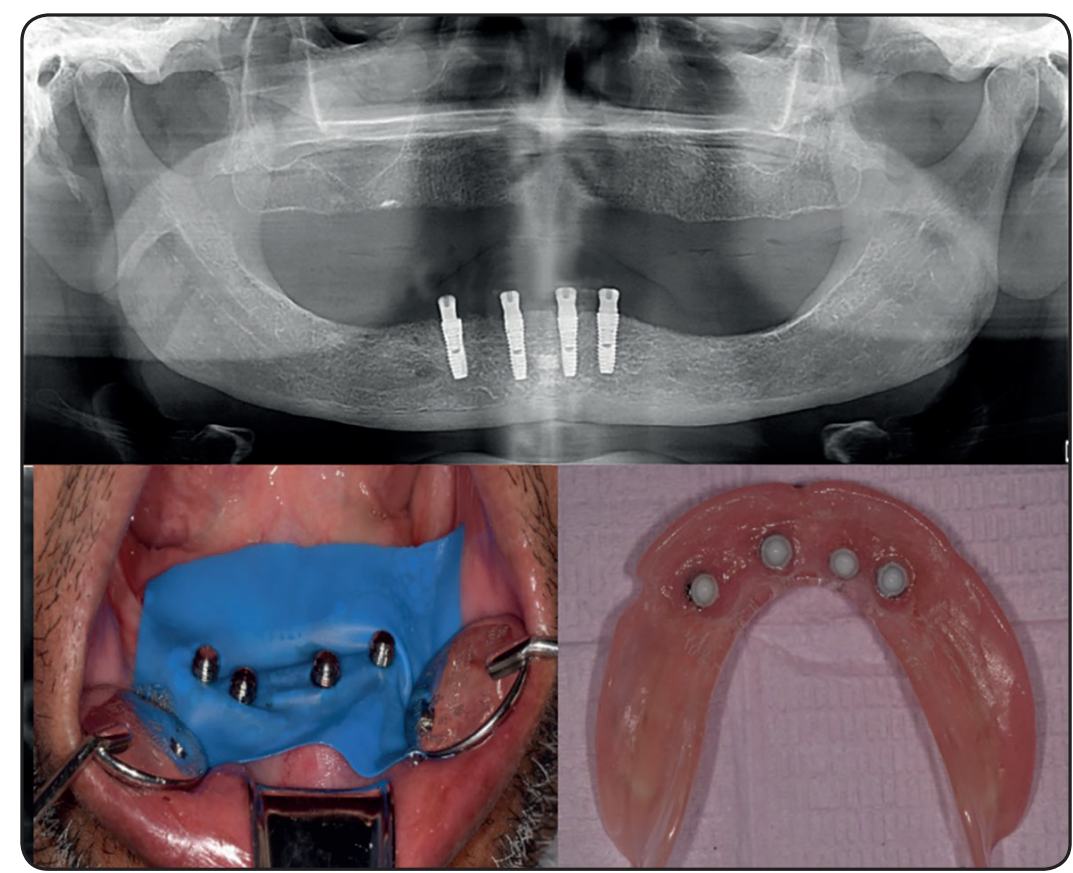

Fig. (2). The overdenture prosthesis group; a) panoramic x-ray of the locator abutments, b) rubber dam sheets around locator abutments and metal housings snapped on locator abutments, c) nylon inserts picked up to the fitting surface of the overdentures 
insertion, one year, and 3 years after insertion. For standardization purposes, CBCT was acquired for all participants with the same acquisition time (14.7 second), voxel size and slice thickness. The data of the CBCT was saved using DICOMs files format on separate $\mathrm{CD}$. The Three-Dimensional marginal bone loss was evaluated in the mesiodistal and buccolingual directions around each implant. The changes in bone height were calculated at mesial, distal, buccal and lingual surface of each implant. In the axial window of the software of the CBCT machine (OnDemand3DApp), a panoramic curve was made to bisect each implant mesiodistally from the occlusal view. The images were reconstructed by the software in the cross-surface sectional image view for each implant. Vertical bone height was evaluated at the panoramic window of the software to measure bone height changes at mesial and distal surface of each implant (fig3). Vertical bone height was evaluated at cross surface sectional image to measure bone height changes at buccal and lingual surface of each implant (fig3). To estimate marginal bone loss at all surfaces, the distance from implant abutment junction (point A) to the bone contact with implant (point B) was measured using the ruler measure tool of the software to give bone level ${ }^{26}$.
Bone loss was calculated by evaluation of bone height changes from base line to one year and 3 years. The bone loss measurement for mesial and distal buccal and lingual surfaces were averaged for all implants and the mean was subjected to statistical analysis. To evaluate the reliability of obtained data, three independent examiners performed the measurements.

\section{Statistical analysis}

A computer program was used for analyzing the data of marginal bone loss (statistical package for social science, SPSS v25.0). The values of marginal bone loss were tested for normal distribution using Shapiro Wilk test and Kolmogorov Smirnov test. The values met normal distribution and the data was parametric. The inter-examiner reliability was tested using Alpha Cronbach test. Two-way repeated measures analysis of variance (AVOVA) was used to compare marginal bone loss between groups (fixed prosthesis and overdenture prosthesis), implant surfaces (mesial, distal, buccal, and lingual), and observation times (baseline, one year, and three years). When a significant difference was detected, multiple pairwise comparisons were performed using Tukey test. P value is significant at .05 .

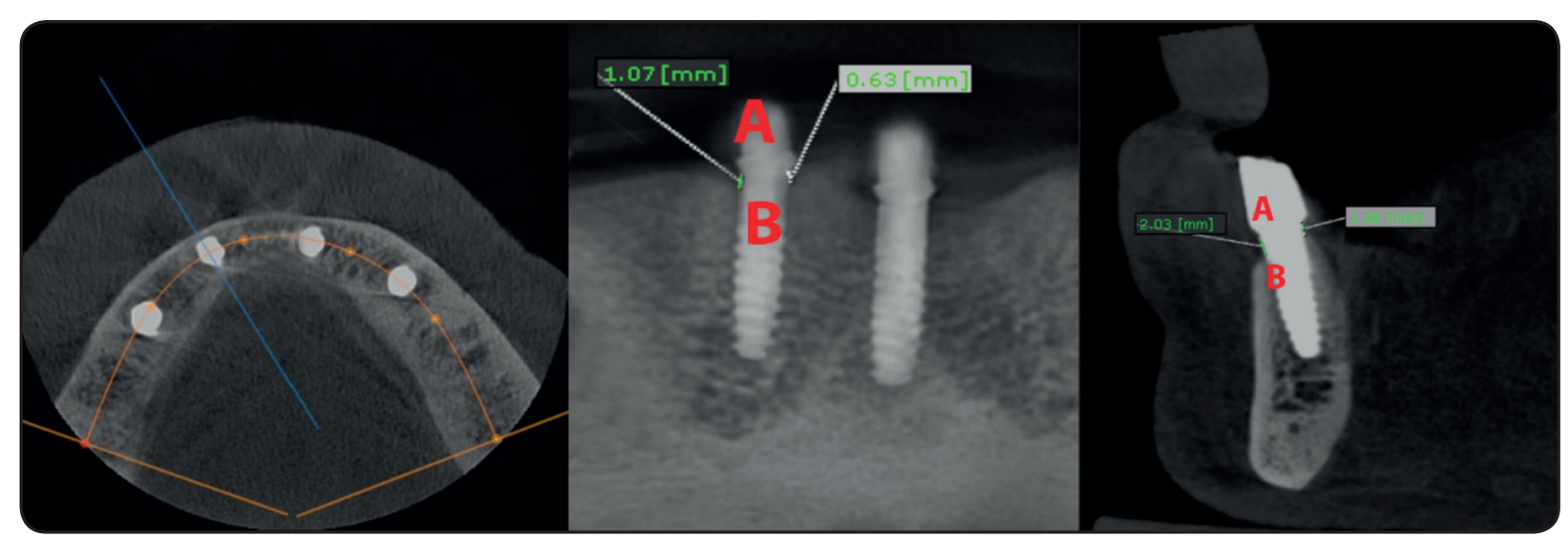

Fig. (3): Three-Dimensional Measurements of marginal bone loss, a) panoramic curve that bisected the implant mesiodistally, b) measurement of bone loss at mesial and distal aspects of implants at panoramic images, c) measurement of bone loss at buccal and lingual aspects of implants at cross sectional images 


\section{RESULTS}

All participants attended the follow-up visits without dropouts. No implant failures occurred in both groups and the survival rate was $100 \%$ in each group. The data of marginal bone loss values for all examiners were compared using alpha Cronbach test and the resultant correlation coefficient of the test was more than 0.80 which means that the data of marginal bone loss values were reliable. The mean values of the total marginal bone resorption after one year were $.36 \pm .14 \mathrm{~mm}$ for fixed prosthesis group and $.73 \pm .28 \mathrm{~mm}$ for the overdenture prosthesis group.

Comparison of peri-implant bone loss between different implant surfaces (distal, lingual, mesial, and buccal) and between groups (fixed and removable prosthesis) after one year of prosthesis insertion is presented in table 1. For all implant surfaces except lingual surface, there was a significant difference in marginal bone resorption between fixed and overdenture groups. The overdenture group showed significantly higher marginal bone loss than fixed prosthesis at distal, mesial, and buccal implant surfaces. However, at lingual surface, there was no significant difference in marginal bone loss between groups. For both groups, there was a significant difference in bone loss between implant surfaces. For fixed prosthesis group, the highest bone resorption was observed in the lingual site followed by mesial site, then distal site and the lowest marginal bone loss was observed at buccal site. Multiple comparison between each two implant surfaces is presented in the same table. There was no significant difference between distal and mesial sites. For overdenture group, the highest bone loss observed at the buccal site, followed by mesial site, then distal site, and the lowest one loss was observed at lingual site. Multiple comparison between each two implant surfaces is presented in the same table. No significant difference was observed between distal and lingual site

Comparison of peri-implant bone loss between different implant surfaces (distal, lingual, mesial, and buccal) and between groups (fixed and removable prosthesis) after 3 years of prosthesis insertion is presented in table 2. For all implant surfaces except lingual surface, there was a significant difference in marginal bone resorption between fixed and overdenture groups. The overdenture group showed significantly higher marginal bone loss than fixed prosthesis at distal, mesial, and buccal implant surfaces. However, at lingual surface, there was no significant difference in marginal bone loss between groups. For both

TABLE (1). Marginal bone loss at different implant surfaces for fixed and removable prosthesis after one year of prosthesis insertion

\begin{tabular}{|c|c|c|c|c|c|}
\hline & \multicolumn{2}{|c|}{ Fixed prosthesis } & \multicolumn{2}{|c|}{ Overdenture prosthesis } & \multirow{2}{*}{$\begin{array}{c}\text { Repeated ANOVA } \\
\text { P value }\end{array}$} \\
\hline & Mean & St deviation & Mean & St deviation & \\
\hline Distal & $.32 \mathrm{a}$ & .13 & $.62 \mathrm{a}$ & .31 & $.003 *$ \\
\hline Lingual & $.61 b$ & .26 & $.55 \mathrm{a}$ & .16 & .50 \\
\hline Mesial & $.47 \mathrm{a}$ & .12 & $.81 \mathrm{~b}$ & .26 & $.001 *$ \\
\hline Buccal & $.15 \mathrm{c}$ & .03 & $.97 \mathrm{c}$ & .24 & $<.001 *$ \\
\hline Repeated ANOVA (P value) & \multicolumn{2}{|c|}{$<.001^{*}$} & \multicolumn{2}{|c|}{$<.001 *$} & \\
\hline
\end{tabular}

*; P is significant at 5\% level of significance, different letters in the same column indicate a significant difference between each two implant surfaces (Bonferroni test, $P<.05$ ). While the same letters showed no significant difference between each two implant surfaces (Bonferroni test, $P>.05$ ) 
groups, there was a significant difference in bone loss between implant surfaces. For fixed prosthesis group, the highest bone resorption was observed in the lingual site followed by mesial site, then distal site and the lowest marginal bone loss was observed at buccal site. Multiple comparison between each two implant surfaces is presented in the same table. There was no significant difference between distal and mesial sites. For overdenture group, the highest bone loss observed at the buccal site, followed by mesial site, then lingual site, and the lowest one loss was observed at distal site. Multiple comparison between each two implant surfaces is presented in the same table. No significant difference was observed between distal, mesial and lingual site.

Comparison of marginal bone loss at different peri-implant surfaces between one and 3 years is presented in fig 4 for fixed prosthesis and in fig 5 for overdenture prostheses. For both groups at different the implants the surfaces, marginal bone loss occurred after three years recorded significant higher values compared to marginal bone loss occurred after one year $(\mathrm{p}<.05)$

TABLE (2) Marginal bone loss at different implant surfaces for fixed and removable prosthesis after one year of prosthesis insertion

\begin{tabular}{|c|c|c|c|c|c|}
\hline & \multicolumn{2}{|c|}{ Fixed prosthesis } & \multicolumn{2}{|c|}{ Overdenture prosthesis } & \multirow{2}{*}{$\begin{array}{c}\text { Repeated ANOVA } \\
\text { P value }\end{array}$} \\
\hline & Mean & St deviation & Mean & St deviation & \\
\hline Distal & $.84 \mathrm{a}$ & .22 & $1.08 \mathrm{a}$ & .23 & $.015^{*}$ \\
\hline Lingual & $1.23 \mathrm{~b}$ & .45 & $1.14 \mathrm{a}$ & .14 & .34 \\
\hline Mesial & $.90 \mathrm{a}$ & .16 & $1.21 \mathrm{a}$ & .14 & $.002 *$ \\
\hline Buccal & $.52 \mathrm{c}$ & .28 & $1.36 \mathrm{~b}$ & .42 & $<.001 *$ \\
\hline Repeated ANOVA (P value) & \multicolumn{2}{|c|}{$.002 *$} & \multicolumn{2}{|c|}{$.022 *$} & \\
\hline
\end{tabular}

*; P is significant at 5\% level of significance, different letters in the same column indicate a significant difference between each two implant surfaces (Bonferroni test, $P<.05$ ). While the same letters showed no significant difference between each two implant surfaces (Bonferroni test, $P>.05$ )

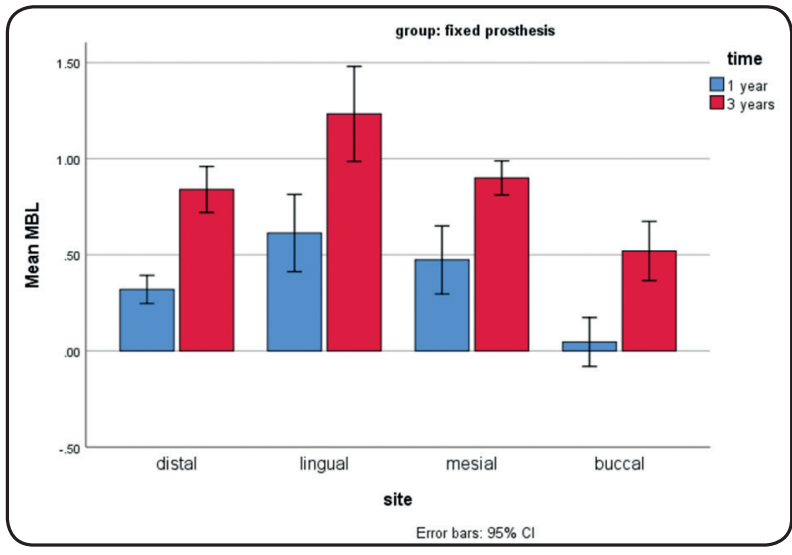

Fig. (4). Comparison of marginal bone loss between one year and three years after prosthesis insertion for fixed prosthesis group

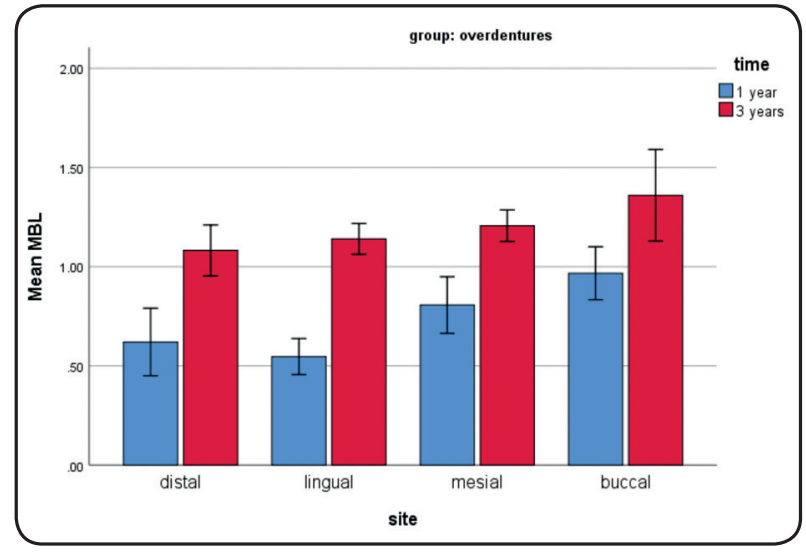

Fig. (5). Comparison of marginal bone loss between one year and three years after prosthesis insertion for overdenture group 


\section{DISCUSSION}

In this study, CBCT was utilized for evaluation of bone loss around the implant as it enables ThreeDimensional marginal bone height evaluation in mesiodistal and buccolingual directions. In panoramic view of CBCT, mesial and distal marginal bone height changes can be evaluated, while in the cross-sectional view of the CBCT, buccal and lingual marginal bone height changes can be assessed. Conversely, the two-dimensional nature of the periapical radiography allows only measurement of mesial and distal bone heights and overlook the importance of measuring buccal and lingual bone resorption. Another benefit of using CBCT is avoidance of patient discomfort and trauma of the floor of the mouth caused by orientation of the film holder of the periapical radiography especially in patients with high floor of the mouth with atrophied mandibular ridges. Moreover, CBCT can provide direct and actual measurements using the accompanying software without magnification ${ }^{19,20}$. The use of CBCT in measuring the implant alveolar bone changes was recommended by several authors with acceptable accuracy ${ }^{26-34}$ when implants used to support fixed and removable restorations. However, it should be noted that CBCT are associated with increased dose of radiation compared to conventional periapical radiograph. Therefore, the evaluation period was extended to be after one year and three years of prosthesis insertion to reduce the harmful effect of increased radiation dose. Another limitation of the CBCT is the increased image noise caused by metal artefacts. However, this noise was founded to have minimal effect on marginal bone height measurements. ${ }^{35}$

The implant survival rate was $100 \%$ for fixed and removable prosthesis. This observational was on line with a recent systematic review in which the authors reported high survival rates for implants used to support fixed and removable implant fullarch prostheses in the mandible ${ }^{36}$. The mean values of the total marginal bone resorption after one year were $.36 \pm .14 \mathrm{~mm}$ for fixed prosthesis group and $.73 \pm .28 \mathrm{~mm}$ for the overdenture prosthesis group. The overall marginal bone loss for both groups did not exceed $1 \mathrm{~mm}$ after one and three years. Similarly, Makkonen et al. reported that mean bone loss after 3 years was $.25 \pm .16$ and $.53 \pm .38$ for fixed prosthesis and overdentures respectively. This amount of marginal bone loss is located in the normal range that was reported in earlier investigations (not more than $1 \mathrm{~mm}$ in the first year and less than $.2 \mathrm{~mm}$ annually $)^{13}$. The values of marginal bone loss in both groups were in line with recent systematic review $^{37}$ in which the authors reported that marginal bone loss ranged from $0.17 \pm 0.07 \mathrm{~mm}$ to $2.1 \pm$ $1.6 \mathrm{~mm}$ for fixed prosthesis and from $0.22 \pm 0.55 \mathrm{~mm}$ to $2.5 \pm 2.7 \mathrm{~mm}$ for overdentures. The high survival rate and the reduced level of total marginal bone loss may be attributed to the increased bone quality and density of mandibular bone which provide good primary stability of the implants. Moreover, the delayed loading approach used in both groups may be contributed to the high survival rate and the reduced bone loss as it reduces micromotions to the implants in the critical healing period.

For all implant surfaces except lingual surface, the overdenture group showed significantly higher marginal bone loss than fixed prosthesis after one years and 3 years. Similarly in a recent systematic review ${ }^{37}$ the authors reported that marginal bone loss was initially higher in removable implant-supported prosthesis (overdentures) than fixed prosthesis after one year but bone loss does not differ between the groups after 4 years. The increased bone loss the overdenture group may be attributed to the slight implant disparallelism in mesiodistal and buccolingual directions. Although an attempt was made to make the implant parallel to each other's, slight implant disparallelism may exists due to values of conventional stent. Moreover, buccal or lingual undercuts may demand implant placement with the slight buccal or lingual inclination. The 
locator nylon inserts have dual retention comes from internal and external frictional flanges so it may act as guiding planes during insertions and removals of the overdenture. The slight disparallelism may create undercuts between nylon inserts and locator abutments which may transmit increased forces to the implants during insertion and removal. Moreover, the double frictional flanges provide limited hinge movement of the attachment while overdenture rotates during mastication ${ }^{38}$ which may be responsible for transferring more loads to the implant, thus increasing bone loss. In line with this explanation, Elsyad et al. ${ }^{39-42}$ reported increased peri-implants stresses with locator retained mandibular overdentures supported by two implants when implant inclination increased. These stresses may be aggravated by use of four implants as multiple guiding implants are created. Therefore, it may be adventurous in terms of periimplant bone preservation to use computer guided surgery with prefabricated stereolithographic stent to ensure implant parallism when 4-implant are used to support overdentures with locator attachments. On the other hand, the reduced marginal bone loss and the fixed group may be attributed to several factors. Firstly, the fixed prosthesis has more support by the effect of increased implant number posterior to the mental foramina (six implants Vs four implants the overdenture group) which may provide more load distribution as fixed prosthesis not rotated during function such as overdentures. Secondly, the passive fit of the framework of the prosthesis was tested before insertion, thus ensuring minimal load transmission to the implants. Firstly, the implant disparallelism is compensated by the use of ti-base abutments. Finally, with fixed prosthesis, the implants are splinted together by the rigid metal framework of the prosthesis which may provide provide greater surface area, more load sharing between implants and prevent implant micromotions ${ }^{43}$. In line with this observation, a 3-D finite element $s^{1}{ }^{18}$ found that fixed prosthesis showed significantly lower stresses in the implant cortical bone tissues than overdentures supported by four connected implants with cantilevered bar attachments.

It was interesting to find that, in fixed prosthesis group, the highest bone resorption after one and 3 years was observed in the lingual site and for the overdenture group, the highest bone loss was observed at the buccal site. Reviewing the literature, no study evaluated the marginal bone loss on different peri-implant sites especially the buccal and lingual sites was fixated implant-supported versus. Therefore, comparison of the results of this study was finding of other studies was not possible. The increased marginal bone loss on the lingual site the fixed group may be attributed to increased occlusal forces from functional palatal cusps of maxillary dentures on the mandibular fixed prostheses in which the crowns are directly to the lingual. Owing to mandibular bone atrophy, a crossbite relation may exists between maxillary and mandibular bone. In an attempt to establish good occlusal relation in centric occlusion, the crowns of fixed procedures are usually tilted lingually. This may cause increased occlusal load transmitted to the lingual cortex around the implants and maybe responsible for increased bone loss in the lingual sites. On the other hand, the increased bone loss on the buccal site and overdenture group may be due to the presence of buccal flange of mandibular overdenture which may cause mucosal stripping, inflammation around implants during insertions and removals of the prosthesis with subsequent bone loss. In line with this observation, Elsyad et al. ${ }^{26}$ found that the buccal site were associated with the highest bone resorption when 2 implant are used to retain overdentures with ball and bar attachments. The increased marginal bone loss on lingual and buccal sites of fixed and removable prosthesis is in line with finding of an in vitro study ${ }^{44}$ in which the authors found an increase of buccal and lingual peri implant stresses near the implant neck as the upper edges of the cortical bone plate had the potential 
tendency to be displaced inward and outward in the horizontal plane. The presence of the rigid implant hindered these displacements and led to the occurrence of compressive and tensile stresses on the buccal and lingual sides

For both groups, bone loss after 3 years was significantly higher than after one year. This could be attributed to the increased occlusal load with time and maturation of bone after installation of the implants ${ }^{13}$. The limitations of this study include small patient cohort, and the lack for evaluation of other clinical parameters such as periodontal indices, implant stability, probing depth, and patient satisfaction. Therefore, future randomized clinical trials with sufficient sample size are still needed

\section{CONCLUSION}

Within the limits of this randomized controlled study, Fixed prosthesis was associated with reduced Three-Dimensional marginal bone loss compared to overdentures prosthesis after one and three years of prosthesis insertion. The highest bone loss observed at lingual site for fixed prosthesis group, and buccal site for overdenture group

\section{REFERENCES}

1. Dierens M, Collaert B, Deschepper E, Browaeys H, Klinge B, De Bruyn H. Patient-centered outcome of immediately loaded implants in the rehabilitation of fully edentulous jaws. Clin Oral Implants Res 2009; 20: 1070-1077.

2. Sadowsky SJ. The implant-supported prosthesis for the edentulous arch: design considerations. J Prosthet Dent 1997; 78: 28-33.

3. Misch C. Dental Implant Prosthetics. 2nd Ed. Elsevier Mosby. 2015: 576-577.

4. Zitzmann NU, Marinello CP. Treatment outcomes of fixed or removable implant-supported prostheses in the edentulous maxilla. Part II: clinical findings. J Prosthet Dent 2000; 83: 434-442.

5. Malo P, Rangert B, Nobre M. "All-on-Four" immediatefunction concept with Branemark System implants for completely edentulous mandibles: a retrospective clinical study. Clin Implant Dent Relat Res 2003; 5 Suppl 1: 2-9.

6. ELsyad MA, Elgamal M, Mohammed Askar O, Youssef Al-Tonbary G. Patient satisfaction and oral health-related quality of life (OHRQoL) of conventional denture, fixed prosthesis and milled bar overdenture for All-on-4 implant rehabilitation. A crossover study. Clin Oral Implants Res 2019.

7. Roccuzzo M, Bonino F, Gaudioso L, Zwahlen M, Meijer HJ. What is the optimal number of implants for removable reconstructions? A systematic review on implant-supported overdentures. Clin Oral Implants Res 2012; 23 Suppl 6: 229-237.

8. Chee W, Jivraj S. Treatment planning of the edentulous mandible. Br Dent J 2006; 201: 337-347.

9. Zitzmann NU, Marinello CP. A review of clinical and technical considerations for fixed and removable implant prostheses in the edentulous mandible. Int J Prosthodont 2002; 15: 65-72.

10. Mericske-Stern RD, Taylor TD, Belser U. Management of the edentulous patient. Clin Oral Implants Res 2000; 11 Suppl 1: 108-125.

11. Abi Nader S, Eimar H, Momani M, Shang K, Daniel NG, Tamimi F. Plaque Accumulation Beneath Maxillary Allon-4 Implant-Supported Prostheses. Clin Implant Dent Relat Res 2015; 17: 932-937.

12. Bedrossian E, Sullivan RM, Fortin Y, Malo P, Indresano T. Fixed-prosthetic implant restoration of the edentulous maxilla: a systematic pretreatment evaluation method. J Oral Maxillofac Surg 2008; 66: 112-122.

13. Albrektsson T, Zarb G, Worthington P, Eriksson AR. The long-term efficacy of currently used dental implants: a review and proposed criteria of success. Int $\mathrm{J}$ Oral Maxillofac Implants 1986; 1: 11-25.

14. Albrektsson T, Zarb GA. Current interpretations of the osseointegrated response: clinical significance. Int $\mathrm{J}$ Prosthodont 1993; 6: 95-105.

15. Qian J, Wennerberg A, Albrektsson T. Reasons for marginal bone loss around oral implants. Clin Implant Dent Relat Res 2012; 14: 792-807.

16. Tabata LF, Rocha EP, Barao VA, Assuncao WG. Platform switching: biomechanical evaluation using threedimensional finite element analysis. Int J Oral Maxillofac Implants 2011; 26: 482-491. 
17. Tokuhisa M, Matsushita Y, Koyano K. In vitro study of a mandibular implant overdenture retained with ball, magnet, or bar attachments: comparison of load transfer and denture stability. Int J Prosthodont 2003; 16: 128-134.

18. Barao VA, Delben JA, Lima J, Cabral T, Assuncao WG. Comparison of different designs of implant-retained overdentures and fixed full-arch implant-supported prosthesis on stress distribution in edentulous mandible-a computed tomography-based three-dimensional finite element analysis. J Biomech 2013; 46: 1312-1320.

19. Raes F, Renckens L, Aps J, Cosyn J, De Bruyn H. Reliability of circumferential bone level assessment around single implants in healed ridges and extraction sockets using cone beam CT. Clin Implant Dent Relat Res 2013; 15: 661-672.

20. Naitoh M, Hayashi H, Tsukamoto N, Ariji E. Labial bone assessment surrounding dental implant using conebeam computed tomography: an in vitro study. Clin Oral Implants Res 2012; 23: 970-974.

21. Quirynen M, Alsaadi G, Pauwels M, Haffajee A, van Steenberghe D, Naert I. Microbiological and clinical outcomes and patient satisfaction for two treatment options in the edentulous lower jaw after 10 years of function. Clin Oral Implants Res 2005; 16: 277-287.

22. Tinsley D, Watson CJ, Russell JL. A comparison of hydroxylapatite coated implant retained fixed and removable mandibular prostheses over 4 to 6 years. Clin Oral Implants Res 2001; 12: 159-166.

23. ELsyad MA, Dayekh MA, Khalifa AK. Locator Versus Bar Attachment Effect on the Retention and Stability of Implant-Retained Maxillary Overdenture: An In Vitro Study. J Prosthodont 2019; 28: e627-e636.

24. ELsyad MA, Emera RM, Ashmawy TM. Effect of Distal Implant Inclination on Dislodging Forces of Different Locator Attachments Used for Mandibular Overdentures: An In Vitro Study. J Prosthodont 2019; 28: e666-e674.

25. ELsyad MA, Emera RM, Ibrahim AM. Effect of Labial Implant Inclination on the Retention and Stability of Different Resilient Stud Attachments for Mandibular Implant Overdentures: An In vitro Study. Int J Oral Maxillofac Implants 2019; 34: 381-389.

26. Elsyad MA, Khirallah AS. Circumferential bone loss around splinted and nonsplinted immediately loaded implants retaining mandibular overdentures: A randomized controlled clinical trial using cone beam computed tomography. J Prosthet Dent 2016; 116 741-748
27. Razavi T, Palmer RM, Davies J, Wilson R, Palmer PJ. Accuracy of measuring the cortical bone thickness adjacent to dental implants using cone beam computed tomography. Clin Oral Implants Res 2010; 21: 718-725.

28. Ritter L, Elger MC, Rothamel D, Fienitz T, Zinser M, Schwarz F, Zoller JE. Accuracy of peri-implant bone evaluation using cone beam $\mathrm{CT}$, digital intra-oral radiographs and histology. Dentomaxillofac Radiol 2014; 43: 20130088.

29. Villarinho EA, Correia A, Vigo A, Ramos NV, Pires Vaz MA, Arai Shinkai RS. Volumetric Bone Measurement Around Dental Implants Using 3D Image Superimposition: A Methodological and Clinical Pilot Study. Int J Prosthodont 2018; 31: 23-30.

30. ELsyad MA, Abdraboh AE, Aboelnagga MM, Ghali RM, Lebshtien IT. Effect of Low-Level Laser Irradiation on Stability and Marginal Bone of Narrow Implants Retaining Overdentures in Moderately Controlled Diabetic Patients. J Oral Implantol 2019; 45: 391-397.

31. Di Stefano DA, Piattelli A, Zaniol T, Iezzi G. Implant and Prosthetic Success Following Peri-implant Guided Bone Regeneration in the Esthetic Zone Using an Equine Cortical Bone Membrane and an Equine Enzyme-Treated Bone Graft: A Retrospective Study with 9-year Follow-Up. Int J Oral Maxillofac Implants 2020; 35: 824-832.

32. Li Manni L, Lecloux G, Rompen E, Aouini W, Shapira L, Lambert F. Clinical and radiographic assessment of circular versus triangular cross-section neck Implants in the posterior maxilla: A 1-year randomized controlled trial. Clin Oral Implants Res 2020; 31: 814-824.

33. Koutouzis T, Ali A. The Influence of Abutment Macrodesign on Facial Peri-implant Tissue Dimensions for Guided Placed and Restored Implants at Healed Sites: 1-Year CBCT Findings from a Randomized Controlled Clinical Trial. Int J Periodontics Restorative Dent 2021; 41: $277-283$.

34. Song D, Shujaat S, de Faria Vasconcelos K, Huang Y, Politis C, Lambrichts I, Jacobs R. Diagnostic accuracy of $\mathrm{CBCT}$ versus intraoral imaging for assessment of periimplant bone defects. BMC Med Imaging 2021; 21: 23.

35. Shiratori LN, Marotti J, Yamanouchi J, Chilvarquer I, Contin I, Tortamano-Neto P. Measurement of buccal bone volume of dental implants by means of cone-beam computed tomography. Clin Oral Implants Res 2012; 23 : 797-804. 
36. Tsigarida A, Chochlidakis K. A Comparison Between Fixed and Removable Mandibular Implant-Supported FullArch Prostheses: An Overview of Systematic Reviews. Int J Prosthodont 2021; 34: s85-s92.

37. Saravi BE, Putz M, Patzelt S, Alkalak A, Uelkuemen S, Boeker M. Marginal bone loss around oral implants supporting fixed versus removable prostheses: a systematic review. Int J Implant Dent 2020; 6: 20.

38. Chikunov I, Doan P, Vahidi F. Implant-retained partial overdenture with resilient attachments. J Prosthodont 2008; 17: 141-148.

39. Elsyad MA, Abid KS, Elkhalek EA. Effect of Buccal Implant Inclination on Stresses Around Two-ImplantRetained Overdentures with Resilient Stud Attachments. Int J Oral Maxillofac Implants 2017; 32: e135-e142.

40. Elsyad MA, Eltowery SM, Gebreel AA. Peri-implant strain around mesially inclined two-implant-retained mandibular overdentures with Locator attachments. J Oral Sci 2017; 59: 483-490.
41. ELsyad MA, Abo Hatem OE, Shawky AF, Emera RMK. Effect of Different Degrees of Mesial Implant Inclination on the Retention and Stability of Two-Implant Mandibular Overdentures Retained with Stud Attachments: An In Vitro Study. Int J Oral Maxillofac Implants 2018; 33: 259-268.

42. Alameldeen HE, Elsyad MA, Shawky AF, Khirallah AS. The Influence of Implant Inclination on Retention and Periimplant Stresses of Stud-Retained Implant Overdentures During Axial and Nonaxial Dislodgments: An In Vitro Study. Int J Oral Maxillofac Implants 2020; 35: 543-550.

43. Krennmair G, Krainhofner M, Piehslinger E. Implantsupported mandibular overdentures retained with a milled bar: a retrospective study. Int J Oral Maxillofac Implants 2007; 22: 987-994.

44. Kitamura E, Stegaroiu R, Nomura S, Miyakawa O. Biomechanical aspects of marginal bone resorption around osseointegrated implants: considerations based on a threedimensional finite element analysis. Clin Oral Implants Res 2004; 15: 401-412. 